\title{
Rotating Membrane Emulsification for Producing Single and Multiple Emulsions
}

\author{
Nita Aryanti, ${ }^{1, *}$, and Richard A. Williams ${ }^{1}$ \\ ${ }^{1}$ Department of Chemical Engineering, Kampus Undip Tembalang, Semarang, 50278 \\ ${ }^{2}$ Heriot-Watt University, Edinburgh EH14 4AS
}

\begin{abstract}
Membrane emulsification is a technique utilising a novel concept of generating droplet 'drop by drop' to produce emulsions. The technique has several distinctive advantages over the conventional emulsification techniques. This paper concerns on the development of membrane emulsification (Rotating Membrane Reactor, RMR) which utilizes rotating tubular membrane to initiate droplet detachments. The RMR uses a rotating stainless steel tubular membrane with laser drilled pores (100 $\mu \mathrm{m}$ pore diameter) and a syringe pump to drive the dispersed phase through the membrane at a given flow rate. O/W formulations were prepared with low viscosity of paraffin wax, two types of emulsifiers, different membrane rotation rate and dispersed phase flow rate. The emulsion droplets exhibited a coefficient of variation of $9 \%$ and $81 \mu \mathrm{m}$ droplet size. In this research, the pore size/droplet size ratio could achieve 0.8 . This value was below than other membrane emulsification processes. The effects of principal system operating parameters on both the average droplet diameter and droplet uniformity were discussed. In addition, a multiple $(\mathrm{W} / \mathrm{O} / \mathrm{W})$ emulsion formulation was investigated as well.
\end{abstract}

\section{Introduction}

Existing methods for manufacturing emulsions involve droplet break-up using shear or impact stresses. These have some problems relating to emulsion production such as inefficiency of energy used, lack of droplet size and size distribution control and poor equipment reproducibility [1]. In addition, the behaviour of any pair of immiscible phases normally cannot be predicted. The high of energy utilization leads to high cost of manufacture. Furthermore, the quality of the product can vary from one manufacturing vessel design to another.

In order to solve some of these problems, membrane emulsification has been developed as an alternative method for producing emulsions. This method is claimed to be superior in many respects to those existing methods. By using membrane emulsification, size and size distribution of droplets can be carefully controlled through the selection of porous membrane, efflux rate of discontinuous phase, cross flow velocity of continuous phase, etc [1]. It means that the membrane emulsification process can produce a narrow droplets size distribution [2,3], potential to produce monodispersity of emulsions [4] and require lower surfactant [3]. In addition, this equipment has lower apparent shear stress compared to the conventional emulsification process [2,4]. Membrane emulsification also generally require lower energy input $(104-106$ $\left.\mathrm{J} / \mathrm{m}^{3}\right)$ compared with the conventional emulsification $\left(106-109 \mathrm{~J} / \mathrm{m}^{3}\right)[2,3,4]$.

Several recent development reports in the membrane emulsification technology are available in the literature $[2,3,5]$. Due to the advantages of membrane emulsification, this method has been successfully applied for preparation of complex particulate products such as double/multiple emulsions [6]. In more particular, beetroot juice as well as procyanidin-rich extract encapsulated in water-in-oil-in-water $(\mathrm{W} / \mathrm{O} / \mathrm{W})$ emulsions were prepared using premix emulsification system [7,8]. In addition, food-grade $\mathrm{W} 1 / \mathrm{O} / \mathrm{W} 2$ emulsions containing resveratrol or vitamin $\mathrm{B}_{12}$ and garlic extracts $\mathrm{W} 1 / \mathrm{O} / \mathrm{W} 2$ emulsions were prepared by membrane emulsification and stirred cell membrane emulsification, respectively $[9,10]$

This paper investigates development of membrane emulsification system. Droplet detachment is initiated by rotating tubular membranes. In this system, the shear force was developed by the rotating membrane rather than the flowing continuous phase. By applying this system, pump circulation of continuous phase in the system can be eliminated. This has a potential advantage of eliminating the need for pump circulation of the

\footnotetext{
Corresponding author: nita.aryanti@che.undip.ac.id
} 
continuous phase in the system, which can be particularly beneficial when fabrications of coarser emulsion droplets or fragile structured multiphase emulsion and capsule products are concerned, as those delicate structures can be easily destroyed during the circulation. The effects of the membrane rotational speeds, and concentrations of emulsifiers and stabilisers on the droplet size and monodispersity in the production of single phase $\mathrm{O} / \mathrm{W}$ emulsions is discussed. Some preliminary experimental results in using the rotating membrane reactor (RMR) for the fabrication of multiphase $\mathrm{W} / \mathrm{O} / \mathrm{W}$ emulsions is also be presented.

\section{Experimental}

\subsection{Experimental Setup}

Fig. 1 and Fig. 2 illustrate a photographic image and schematic diagram of the experimental apparatus respectively.

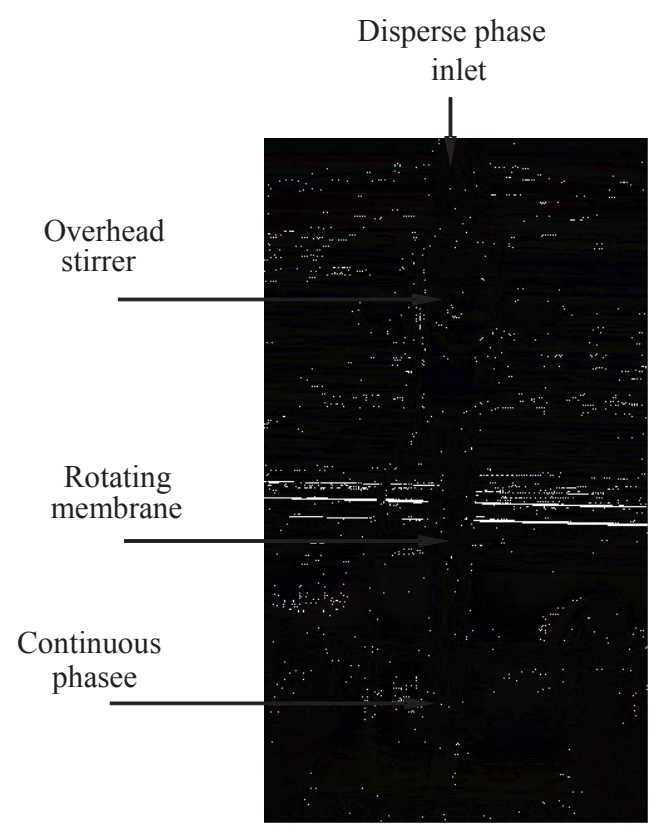

Fig. 1. Photographic image of rotating membrane emulsification device.

The RMR consisted of a tubular membrane made from stainless steel having diameter of $10 \mathrm{~mm}$ and effective length of $85 \mathrm{~mm}$. The membrane was mounted on a digital overhead stirrer (IKA Eurostar), which enables the membrane to rotate in a stationary vessel. The pores of membrane (fabricated via laser drilling) were arranged in a cubic array. The membrane having 100 $\mu \mathrm{m}$ mean pore size and $500 \mu \mathrm{m}$ pore-pore spacing, which correspond to membrane porosity of $3 \%$. In the current work, a standard $100 \mathrm{ml}$ measuring cylinder (diameter $25 \mathrm{~mm}$ ) was used as the stationary vessel.

\subsection{Single Emulsion}

In the single phase emulsion investigation, low viscosity paraffin wax (28mPa.S, Fluka) was used as the disperse phase. As emulsifier, either Tween 20 (polyoxyethylene sorbitan monolaureate) (Fisher Chemical, UK) or sodium dodecyl sulphate (SDS) (Fluka, UK) was used as the emulsifier. Carbomer (Carbopol ETD 2050) (Surfachem Ltd., Leeds, UK) was used as the stabiliser. The dispersed phase was introduced inside the membrane tube by mean of a constant flow syringe pump with adjustable flow rate between 7-211 ml/hr.

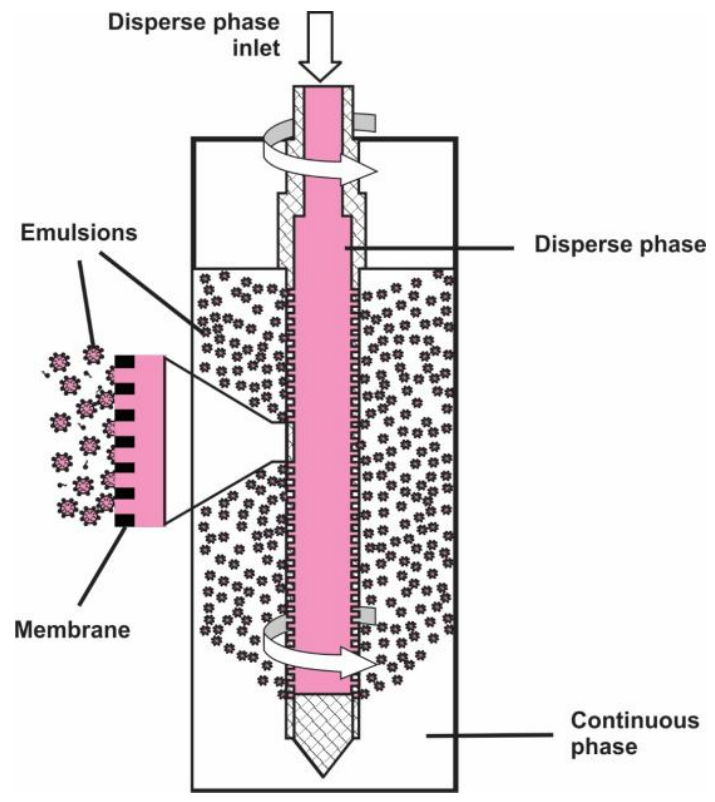

Fig. 2. Schematic illustration of rotating membrane emulsification device, insert showing a microscopic view of the stainless steel membrane.

\subsection{Multiple W/O/W Emulsions}

In the multiphase emulsion investigation, a rapeseed oil was used as the oil phase. Deionised water was employed as both the inner and outer water phase. The $\mathrm{W} / \mathrm{O} / \mathrm{W}$ emulsions were prepared by a two-step emulsification method. In the first step, a single phase W/O emulsion was prepared through homogenisation (Polytron PT2100) at 19,000 rpm for 3 minutes, which produced approximately 1-10 $\mu \mathrm{m}$ water droplets in the rapeseed oil. A lipophilic surfactant, Polyglycerol polyricinoleate (PGPR) (Danisco, Denmark), was added to the oil phase as the emulsifier. The concentration of deionised water in the rapeseed oil was kept constant at $10 \%(\mathrm{w} / \mathrm{w})$. The $\mathrm{W} / \mathrm{O}$ emulsion was then used as the disperse phase for the second step emulsification by $\mathrm{RMR}$, in which the W/O emulsion was carefully injected into the membrane tube using a syringe pump (Razel A99FMZ, from Fisher Scientific), and dispersed into the outer deionised water phase containing 2\% Tween 80 (polyoxyethylene sorbitan monooleate) (Across Organic) as the emulsifier. 


\subsection{Droplet Characterization}

Droplets were examined directly using a digital microscope (Nikon model SMZ800) with 10-63 times magnification. For multiple emulsions, a further analyses was examined using confocal microscope (Nicon Eclipse TE2000-U). The images were then intrepreted by image processing software (Image Pro Plus) for number based distribution. The monodispersity of the droplets was evaluated in terms of the coefficient of variation (CV) which is defined as:

$$
C V=\frac{S_{d}}{D_{\text {avg }}} \times 100 \%
$$

where $\mathrm{Sd}$ and $\mathrm{D}_{\text {avg }}$ represent the standard deviation of droplet diameter and the average droplet diameter respectively. It was suggested that droplets with a CV no higher than $25 \%$ should be considered as monodispersed.

\section{Result and Discussion}

\subsection{Single Emulsion}

Fig. 3 presents the effect of membrane rotation on droplet average diameter at carbomer concentration of $0.1 \%$ at different type of emulsifier. It can be seen that the average droplet diameter initially decreases sharply with the increase of membrane rotation speed no matter the type of emulsifiers used. This phenomenon is likely $\mathrm{du}$ to the shear force at the membrane surface, which is the main droplet detaching force, increases with the increase of the membrane rotational speed [11]. In the meantime, higher membrane rotational speeds also result in shorter droplet growth time. The continuous increase of the membrane rotation speed may force the droplet growth time rapidly approaching its limit, causing the droplet average diameter changes to decrease [12].

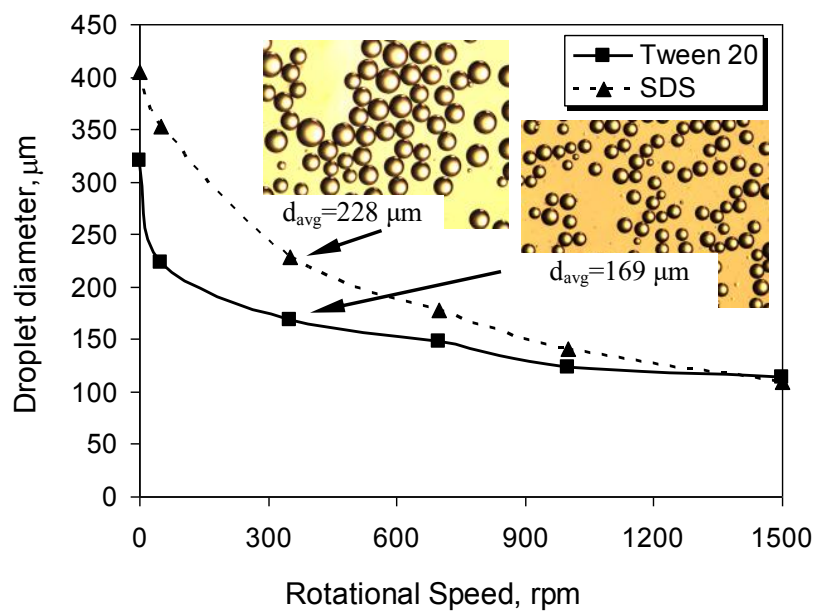

Fig. 3. Effect of membrane rotational speed on droplet size using different type of emulsifier at $0.1 \%(\mathrm{w} / \mathrm{w})$ carbomer concentration, insert showing typical micrograph images at the specific condition.
The type of emulsifier also influences the average droplet diameter. At $0.1 \% \quad(w / w)$ carbomer concentration, Tween 20 produced smaller droplet diameter than SDS. This result is reversed with Schroder et al.'s investigation which is showed that SDS produced smaller droplet than SDS because of the ability of SDS to lower the interfacial tension very quickly [13] This could be attributed to the fact that both SDS and carbomer are anionic surfactants. The migration of SDS molecules from the bulk solution to the droplet surface, therefore, may be prevented by the electrostatic repulsion due to the high level of presence of the carbomer molecules at the interface. Tween 20, on the other hand, is a non-ionic surfactant, therefore, will not be affected.

The effect of dispersed phase flow rate on droplet diameter is shown in Fig. 4, with the $\mathrm{CV}$ is in the range of $9 \%$ to $25 \%$.

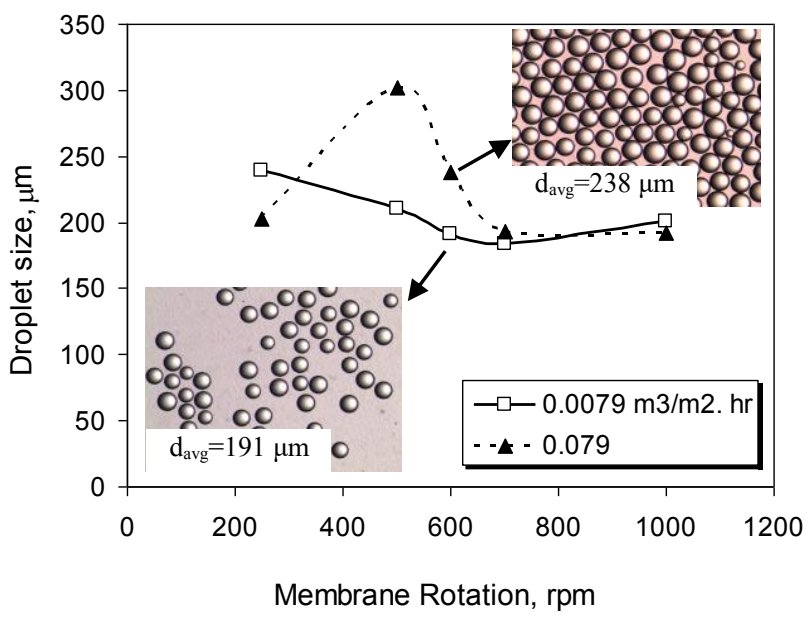

Fig. 4. Effect of membrane rotational speed on droplet size at $0.1 \%(\mathrm{w} / \mathrm{w})$ carbomer concentration with different dispersed phase fluxes, insert showing typical micrograph images at specific condition.

In general, there is a tendency for droplet diameter to decrease with the increase of membrane rotation. However, at different dispersed phase flow rates, the results are slightly different. The increase of dispersed phase flow rate correlates with the increase of inertial force which is play a role in additional detaching force and leading to faster droplet detachment. In the case of higher membrane rotation, the drag force will also increase as the membrane rotation raise. Further detaching force certainly will make the droplet detach more rapidly and droplet detachment period is shorter than in the case of low membrane rotation. This is due to the larger inflow velocity of the dispersed phase in the pore neck which is creating a Bernoulli under-pressure drop that arises as a result of the necking process [13]. The Bernoulli under-pressure drop affects the transmembrane pressure (TMP) of membrane emulsification and resulted in smaller droplets. 
On the other hand, at higher rotation rate, larger droplet diameter was generated with the increase of dispersed phase flow rate. This was due to the rate of emulsifier to stabilise the interface was not fast enough and hence larger droplets were produced. In addition, with the increase of dispersed phase flowrate, a viscous pressure contribution is created. This pressure maintain the pore neck into open longer and the droplets detachment period is finally retarded [14]. As a consequence, the larger droplets are produced. However, when the membrane rotation is higher, the effect of necking process can be diminished by the shear stress of rotation and smaller droplet diameter can be obtained.

\subsection{Multiple W/O/W Emulsions}

Only the preliminary experimental results are available at this stage. Fig. 5 illustrates the effect of the membrane rotational speed on the multiple emulsion droplet size at two levels of inner phase emulsifier concentrations respectively.

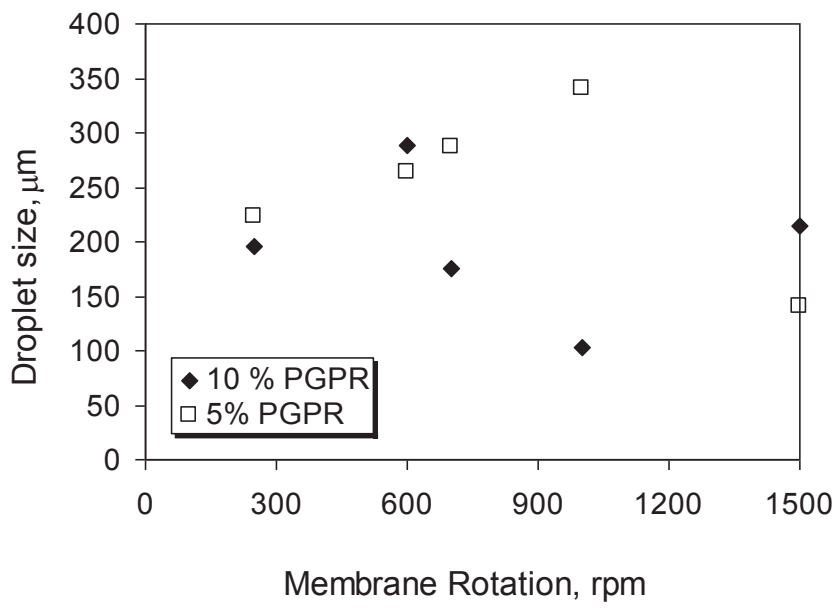

Fig. 5. Effect of inner phase of emulsifier concentration on droplet size.

Fig.5 confirms that application of higher membrane rotation tend to generate smaller droplets as found by previous reports [6]. Preparation of double emulsion by membrane emulsification should have advantage, producing higher encapsulation efficiency compared to higher shear device [15].

The experiments were conducted with the concentration of the outer phase emulsifier (Tween 80) being kept constant at $2 \%$. The coefficient of variation $(\mathrm{CV})$ for $10 \%$ PGPR concentration is in the range of $18 \%$ to $28 \%$, while the $\mathrm{CV}$ for 5\% PGPR concentration is much higher, which is in the range of $19 \%$ to $48 \%$. The result obviously indicates that the concentration of the inner phase emulsifier has a rather strong influence on both the multiple droplet size and monodispersity. PGPR is soluble in oil and usually applied for stabilizing W/O emulsions. However, the concentration of PGPR did not have effect on the droplet size of inner emulsions [16]. Addition of PGPR reduced instability of the processes due to a lower collision efficiency. Experimental works with RMR on W/O/W emulsion production $(10 \%(\mathrm{w} / \mathrm{w})$ PGPR as inner emulsifier and $2 \%(\mathrm{w} / \mathrm{w})$ Tween 80 as outer emulsifier) provide multiple emulsions in the range of $102.2 \mu \mathrm{m}$ to $290.3 \mu \mathrm{m}$. Some images of multiple emulsion and droplet size distribution are showed in Fig. 6 and Fig. 7, respectively.

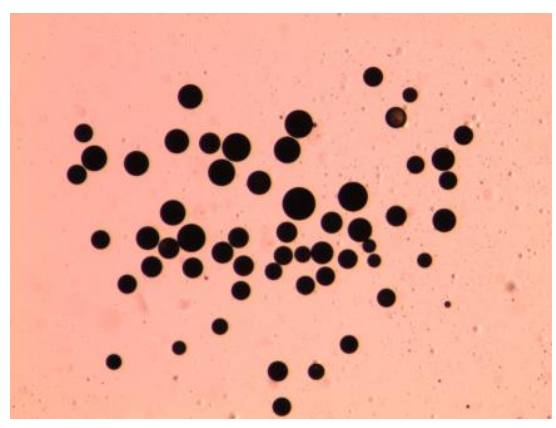

(a)

Davg $=102.2 \mu \mathrm{m}, \mathrm{CV}=20.8 \%$ (1000 rpm, $0.026 \mathrm{~m}^{3} / \mathrm{m}^{2} . \mathrm{hr}$ )

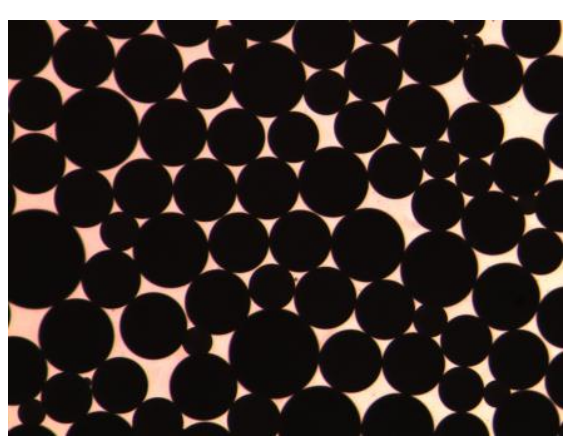

(a)

Davg $=290.3 \mu \mathrm{m}, \mathrm{CV}=24.3 \%$

(700 rpm, $0.053 \mathrm{~m}^{3} / \mathrm{m}^{2} . \mathrm{hr}$ )

Fig. 6. Images of W/O/W emulsion droplets using RMR with $10 \%(\mathrm{w} / \mathrm{w})$ of PGPR as inner emulsifier.

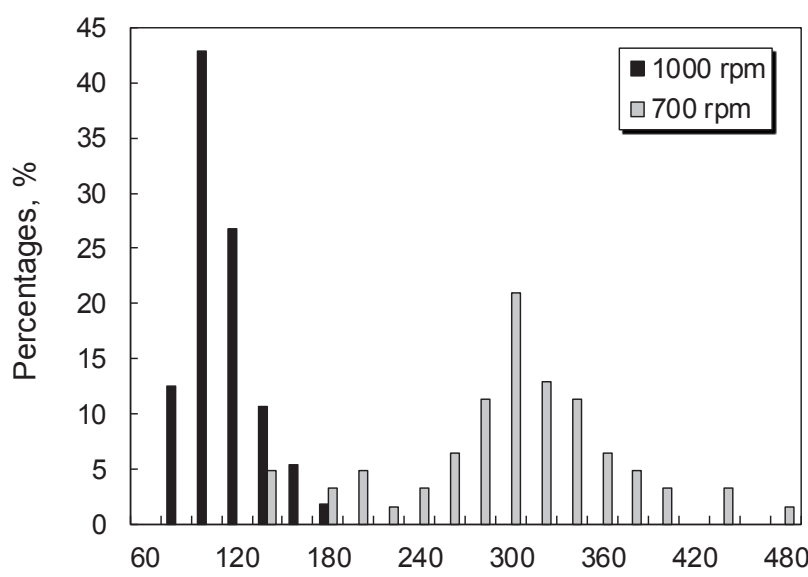

Droplet size, $\mu \mathrm{m}$

Fig. 7. Droplet size distribution of images at Fig. 6 
In a multiple emulsification system, such influences would have to be minimised. Stability of double emulsions was influenced by colaescence inner droplets with the outer droplets. Effect of inner droplet coalesce was reported by Gaitzsch et al. [17] and Schuh et al. $[18,19]$. The interaction between the inner and outer phase surfactants will induce a redistribution of the surfactant molecules on the two interfaces, which may lead to rupture of the oil layer in the $\mathrm{W} / \mathrm{O} / \mathrm{W}$ droplets, and subsequently result in the loss of the internal $\mathrm{W} / \mathrm{O}$ droplets [20]. Fig. 8 shows a photographic image of the droplets produced. The multiple phase structure of the droplets is clearly discernable.

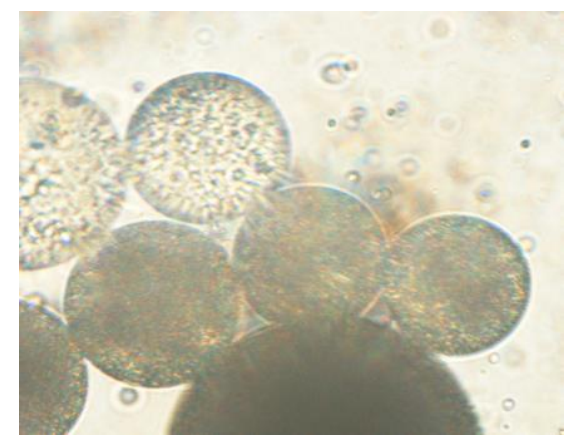

Fig. 8. Micrographic images of the multiphase $\mathrm{WO} / \mathrm{W}$ droplets produced at membrane rotation rate of $700 \mathrm{rpm}$ and dispersed phase flow rate of $0.053 \mathrm{~m}^{3} / \mathrm{m}^{2} . h r$ taken using: Confocal microscope (Nicon Eclipse TE2000-U) at 20× magnification.

\section{Conclusion}

Single $(\mathrm{O} / \mathrm{W})$ emulsions was successfully produced through a rotating membrane emulsification system. In this system, Tween 20 and SDS were used as emulsifier and carbomer was employed as stabilizer. The average droplets sizes at various stabilizer yielded average droplet size in the range of 80 to $210 \mu \mathrm{m}$ with $\mathrm{CV}$ between 10 to $20 \%$. O/W emulsion droplets with average diameter of $130 \mu \mathrm{m}$ to $300 \mu \mathrm{m}$ with coefficient of variation $(\mathrm{CV})$ from $9 \%$ to $25 \%$ were produced at various dispersed phase flow rate. The droplet size and $\mathrm{CV}$ reduced when the dispersed phase flow rate increased. The single phase emulsification experiments indicate that RMR is capable of producing emulsion droplets, which are close to or even smaller than the membrane pore size. This preliminary work has demonstrated the potential application of RMR in manufacturing multiphase $\mathrm{W} / \mathrm{O} / \mathrm{W}$ emulsions. However, the stability of the emulsion droplets need further improvement through a judiciary selection of surfactants, and careful control of the process parameters.

\section{Reference}

1. S. J. Peng, R.A. Williams, Trans IchemE. 76, 894 (1998)

2. Y. Charcosset, I. Limayem H. Fessi, J. Chem. Technol. Biotechnol. 79, 209 (2004)
3. S.M. Joscelyne, G. Trägådh, , J. Membr. Sci. 169, 107 (2000)

4. A.J. Gijsbertsen-Abrahamse,. A. van der Padt, R.M. Boom, J. Membr. Sci. 230, 149 (2004)

5. E. Piacentini, E. Drioli, L.Giorno. J. Membr. Scci. 468, 410 (2014)

6. S.van der Graaf, C.G.P.H.Schroën, R.M.Boom, J. Membr. Sci. 251, 7 (2005)

7. V. Eisinaite, D. Juraite, K. Schroën, D. Leskauskaite, Food Chem. 206, 59 (2016)

8. R. Berendsen, C. Güell, M. Ferrando, Food Hydrocoll. 43, 636 (2015)

9. M. Matos, G. Gutiérrez, O. Iglesias, J. Coca, C. Pazos, J. Food Eng. 166, 212 (2015)

10. J. D. Ilić, B. G. Nikolovski, L. B. Petrović, P. S. Kojić, J. S. Petrović, J. Food Eng. 205, 1 (2017)

11. R.D. Hancocks, F. Spyropoulos, I.T. Norton, J. Membr. Sci. 497, 29 (2016)

12. Q. Yuan, Q., R. A. Williams, N. Aryanti, Adv. Powder Technol. 21(6), 559 (2010)

13. V. Schröder, O. Behrend, H. Schubert, J. Colloids Interface Sci. 202 , 334 (1998)

14. S. Holzapfel, E. Rondeau, P. Muehlich, E. Windhab, Chem. Eng. Tech. 36(10), 1785 (2013)

15. A.K. Pawlik, I.T. Norton, J. Membr. Sci. 415-416, 459 (2012)

16. E. Panagopoulou, V. Evageliou, N. Kopsahelis, D. Ladakis, A. Koutinas, I. Mandala, Coll. Surf.: A. Psycochem. Eng. Aspects 522, 445 (2017)

17. F. Gaitzsch, A. Gäbler, M. Kraume, Chem. Eng. Sci. 66(20), 4663 (2011)

18. A. Schuch, L. G. Leal, H. P.Schuchmann, Colloids Surf., A: Physicochem. Eng. Asp. 461, 336 (2014)

19. A. Schuch, L. G. Leal, H. P.Schuchmann, Coll. Surf. A: Physicochem. Eng. Asp. 461, 344 (2014)

20. A. T. Florence and D. Whitehill, Int. J. Pharm. 11, 277 (1982). 